\title{
A Note on Intergenerational Schooling Mobility
}

\author{
Thomas Bassetti ${ }^{1,2}$ \\ ${ }^{1}$ Department of Economics and Management "Marco Fanno", University of Padua, Padua, Italy \\ ${ }^{2}$ Interuniversity Center for Economic Growth and Development (CICSE), Pisa, Italy \\ Correspondence: Thomas Bassetti, Department of Economics and Management "Marco Fanno", University of \\ Padua, Via del Santo 33, 35123 Padova, Italy. Tel: 39-3393-597-811. E-mail: thomas.bassetti@unipd.it
}

Received: June 14, 2012 Accepted: July 17, 2012 Online Published: August 20, 2012

doi:10.5539/res.v4n4p121 URL: http://dx.doi.org/10.5539/res.v4n4p121

\begin{abstract}
This article studies how parental education affects children's completed years of schooling. Using a long-term survey, we test whether the intergenerational schooling mobility follows a linear or a nonlinear path. In line with some influential theoretical models, we find that the intergenerational link is clearly nonlinear. In particular, using a quantile regression technique and a generalized additive model, we conclude that this relationship has a logistic shape. This evidence suggests that works in which the intergenerational schooling mobility is estimated by using standard linear techniques do not capture salient nonlinearities.
\end{abstract}

Keywords: intergenerational schooling mobility, nonlinear effects, quantile regressions, semiparametric analyses

\section{Introduction}

Schooling is one of the major mechanisms through which intergenerational social mobility is affected. With intergenerational social mobility, we refer to the relationship between the socioeconomic conditions of two contiguous generations. Empirical works on intergenerational schooling mobility aim to estimate the impact of parental education on the children's realized educational attainment. This empirical literature is based on intergenerational income mobility models such as Becker and Tomes $(1979,1986)$ and Solon (1999).

There are many articles studying the link between parental background and schooling of children (see, e.g., Behrman \& Taubman, 1989; Behrman \& Rosenzweig, 2002; De Haan \& Plug, 2011). These studies show the existence of a positive relationship between parents' education and children's education. Haveman and Wolfe (1995) argue that the education of parents is one of the most important factors in explaining children's achievement. The impact of mother's education is usually larger than the father's one.

Researchers have studied different mechanisms behind this relationship. In general, these studies focus on the role played by parenting behaviors in predicting child's success in school. Linver, et al. (2002) and Yeung et al. (2002) study how home environment influences achievement outcomes. Conger et al. (2002) and Mistry et al. (2002) consider the role of other parenting dimensions such as warmness and nurturing. Finally, Halle et al. (1997) and Davis-Kean (2005) emphasize the fact that parents' beliefs have significant effects on the child's education. In particular, Davis-Kean finds that parents' expectations represent an intermediate channel through which other key determinants affect children's achievement outcomes. These determinants are parents' years of schooling, parental warmth and the fraction of time devoted to reading.

Obviously, correlation does not automatically imply any causal link between parents and children's education. Three approaches have been taken to detect the existence of a causal channel going from parental background to children's schooling performances. For instance, collecting data for identical twins and their children, Berhman and Rosenzweig $(2002,2005)$ find that only father's education affects children's attainments. In this way, it is possible to control for genetic factors that can potentially explain child's performances. Other studies use adoptees' education to address the causality issue. Sacerdote (2002), Plug and Vijverberg (2003), and Björklund et al. (2006) find a low intergenerational mobility in adoptive families. Therefore, genetic characteristics play a role in explaining children's attainment. Finally, contributions based on instrumental variables and schooling reforms suggest that father's education is less important than mother's education for the intergenerational transmission of human capital (see Carneiro et al., 2007). To In general, the empirical literature is far from being conclusive. 
Unfortunately, most of these works estimate a linear model without testing the existence of possible nonlinearities. Without addressing any causality issue, we argue that the use of a linear model may lead to biased estimates. That is, independently on the purpose of the study, a researcher should take into account the existence of nonlinear effects in the intergenerational transmission of education. The same conclusion holds for censored data when we use the replacement method proposed by De Haan and Plug (2011).

The reasons for these nonlinearities can be found in models such as Azariadis and Drazen (1990) and Galor and Zeira (1993). According to this literature, given the presence of intergenerational externalities or credit constraints, the accumulation of human capital may follow a logistic path and a poverty trap may arise. (Note 1) This is the reason why the shape of the intergenerational path is so relevant.

To detect the existence of these nonlinearities, we carry out a quantile regression analysis in which each coefficient captures the marginal effect of covariates on the $\tau$-th conditional quantile of the response variable. One advantage of using this technique is that quantile regressions will be more robust in response to large outliers. That is, centering our estimates at different quantiles, we can obtain more complete and robust results.

Although there are studies using quantile regression for educational attainment (see Betts \& Grogger, 2003), since the variability of educational attainments can be too small, we also estimate a generalized additive model (GAM) in which the mother and father's education levels enter the nonparametric part of the model. (Note 2) The main advantage of this technique is that we do not impose an aprioristic model, allowing the data to reveal the shape of the main relationships.

We arrive at two interesting results. First, both methods confirm the nonlinear nature of the intergenerational schooling mobility process. Second, for a Bachelor's Degree, the impact of father's education on the child's education is higher than mother's one.

The rest of the article is organized as follows. Section 2 presents the econometric techniques we use. Section 3 describes the data set. Section 4 reports the results of the analysis, and Section 5 concludes.

\section{Methodology}

Following De Haan and Plug (2011), we start from the following econometric specification:

$$
S_{i}=\alpha+\beta_{F} S_{F, i}+\beta_{M} S_{M, i}+\gamma D G_{i}+\varepsilon_{i},
$$

where $S_{i}$ represents the years of completed schooling for individual $i, S_{F, i}$ and $S_{M, i}$ are her father and mother's education levels, $D G$ is a dummy variable to capture gender differences, and $\varepsilon_{i}$ is an error term. Equation (1) will be estimated by a quantile regression technique, where each coefficient captures the impact of the regressor on the $\tau$-th conditional quantile of the response variable. Formally, we estimate:

$$
Q_{S_{i}}\left(\tau \mid X_{i}\right)=\alpha(\tau)+\beta_{F}(\tau) S_{F, i}+\beta_{M}(\tau) S_{M, i}+\gamma(\tau) D G_{i},
$$

where $\alpha(\tau), \beta_{F}(\tau), \beta_{M}(\tau)$ and $\gamma(\tau)$ represent the marginal impact of each covariate on the $\tau$-th conditional quantile of the response variable. For each quantile, the intercept captures the marginal effect of the average parental background on the child's education.

We estimated Equation (2) by minimizing the weighted sum of (absolute) residuals. This minimization problem is formulated as a standard linear programming problem. Given our sample size, we used an algorithm similar to the one provided by Barrodale and Roberts (1974). (Note 3) This procedure is particularly indicated for relatively large samples. Since integrating the quantile function over the entire support leads to the sample mean, we can obtain an approximation of the OLS effect by simply integrating the quantile coefficients over their domain. However, with very heterogeneous results, this interpretation may be misleading.

Constructing reliable confidence intervals can be rather difficult in a quantile regression framework. This is due to the fact that the asymptotic covariance matrix depends on the (conditional) error density function estimated at zero. We attempted to estimate a sandwich form of this matrix; however, because adjacent quantile surfaces overlap many times, negative estimates occurred. (Note 4) Therefore, we decided to estimate the kernel specification proposed by Newey and Powell (1990). This methodology provides interval estimates that are asymptotically efficient when errors are non-iid. (Note 5)

Because $\beta_{F}$ and $\beta_{M}$ change along the quantile regression, we also estimated a generalized additive model (GAM) in which the mother and father's education levels enter the nonparametric part of the semi-parametric model. In this case, Equation (1) becomes 


$$
S_{i}=\alpha+f\left(S_{F, i}\right)+g\left(S_{M, i}\right)+\gamma D G_{i}+\varepsilon_{i}
$$

Here, $f($.$) and g($.$) are two a priori unknown functions and represent the nonparametric component of the model.$ Following Wood (2006), the impact of control variables is estimated by iteratively re-weighted least squares. The nonparametric term is obtained by using a quadratically penalized GLM in which the appropriate degrees of freedom are determined by generalized cross-validation. This technique allows us to check the consistency and robustness of our results.

\section{Data}

Data comes from the Wisconsin Longitudinal Study (hereafter WLS). This is a long-term sample containing information on 10,317 graduates from Wisconsin high schools in 1957. The WLS provides data on many social dimensions such as intergenerational relationships, donations, household management, expenditures and health. Data was gathered from graduates if available or their parents. The entire dataset consists of five waves: 1957, 1964, 1975, 1992, and 2004. In 2004, the sample also contains data on graduates' spouses.

We consider those questions on the attainment levels of respondents with children during the following three waves: 1975, 1992 and 2004. The main information refers to completed years of schooling for children and parents. Descriptive statistics are reported in Table 1.

Table 1. Descriptive statistics

\begin{tabular}{llllll}
\hline & Mean & Std. Dev. & (Min, Max) & Skewness & Kurtosis \\
\hline Years of schooling (child) & 14.50 & 2.30 & $(9,24)$ & 0.33 & 2.66 \\
Years of schooling (mother) & 12.91 & 1.72 & $(4,20)$ & 1.23 & 4.01 \\
Years of schooling (father) & 13.62 & 2.67 & $(3,24)$ & 0.77 & 3.32 \\
Gender (daughter=1) & 14.50 & 0.50 & $(0,1)$ & 0.04 & 1.00 \\
\hline
\end{tabular}

As additional controls, we include the child's age and gender. In 2004, married respondents with children were 5,660; however, for 316 out of 5,660 individuals relevant information is missing. We include in our regressions only individuals for whom data are available in the three waves. Therefore, the final sample consists of 4,097 observations. We use the WLS because in this way our quantile coefficients can be directly compared with De Haan and Plug's findings. However, one can argue that the WLS is a nonrepresentative sample. In fact, by construction, the WLS undersamples individuals with low education levels. First, a local linear polynomial estimator is more robust than a simple OLS estimator when the support of covariates is a subset of the entire domain. Second, on the basis of De Haan and Plug's results, we check the robustness of our conclusions by estimating a GAM also for two commonly used datasets: the National Longitudinal Survey of Youth (NLSY) and the Panel Study of Income Dynamics (PSID, University of Michigan). The PSID is a survey started in 1968. The entire sample considers about 5,000 families. In our subsample, low-income households are overweighed. In this survey, mothers were asked to formulate their expectations regarding the final education achievement of their children. Our dataset contains 1936 observations and we also know fathers' education levels. Finally, we also use the 1996 wave of the NLSY. We consider 1,587 families, excluding separated parents. As for the PSID, even in this case the focus is on mothers' expectations. For a detailed description of these samples, we refer to De Haan and Plug (2011).

\section{Results}

Figure 1 presents the quantile regressions for Equation (2). Note that the quantile regression estimates lie outside mean regression confidence interval indicating that this technique provides further information regarding the process of intergenerational schooling diffusion. The noncoverage probability for the confidence intervals is $5 \%$. 

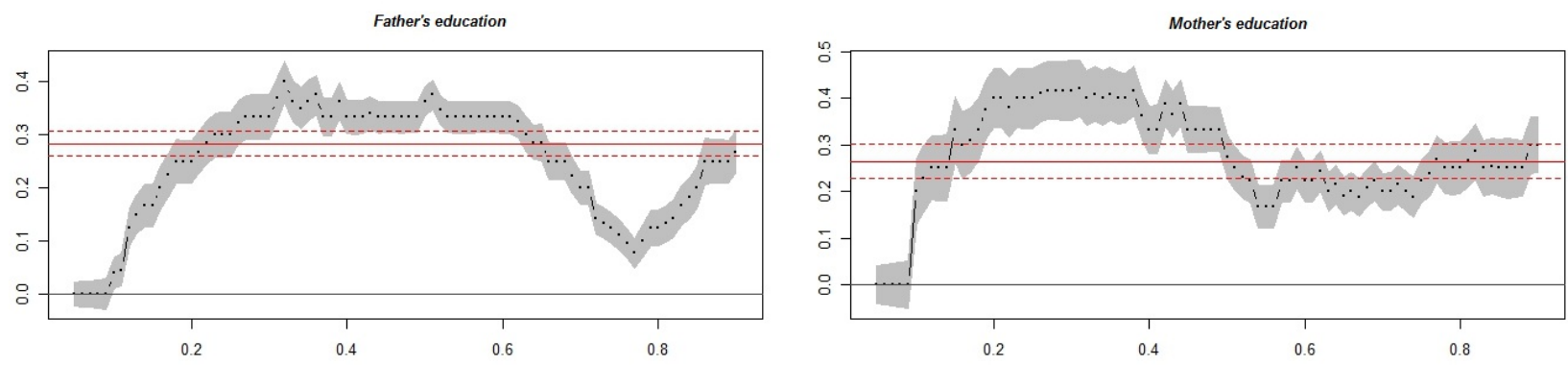

Figure 1. Coefficient plots (quantile regressions)

According to Figure 1, the years of schooling of the older generation matter to explain realized attainment levels. A synthesis of these results is provided in Table 2, where we report only the coefficients at the decile level. In Table 2, we can see that, for the 5-th and the 6-th decile, the coefficient on father's education is higher than the mother's coefficient. These deciles correspond to attainments between 14 and 16 years of schooling.

Table 2. Quantile regressions

\begin{tabular}{|c|c|c|c|c|c|c|c|c|c|}
\hline & 0.1 & 0.2 & 0.3 & 0.4 & 0.5 & 0.6 & 0.7 & 0.8 & 0.9 \\
\hline Intercept & $\begin{array}{l}9.08 * * \\
(0.55)\end{array}$ & $\begin{array}{l}4.20 * * \\
(0.31)\end{array}$ & $\begin{array}{l}3.00 * * \\
(0.28)\end{array}$ & $\begin{array}{l}4.67 * * \\
(0.28)\end{array}$ & $\begin{array}{l}5.82 * * \\
(0.34)\end{array}$ & $\begin{array}{l}7.33^{* *} \\
(0.36)\end{array}$ & $\begin{array}{l}10.4^{* *} \\
(0.40)\end{array}$ & $\begin{array}{l}11.5^{* *} \\
(0.34)\end{array}$ & $\begin{array}{l}9.20 * * \\
(0.36)\end{array}$ \\
\hline Father & $\begin{array}{l}0.04 * * \\
(0.02)\end{array}$ & $\begin{array}{l}0.25 * * \\
(0.02)\end{array}$ & $\begin{array}{l}0.33 * * \\
(0.03)\end{array}$ & $\begin{array}{l}0.33 * * \\
(0.03)\end{array}$ & $\begin{array}{l}0.36^{* *} \\
(0.02)\end{array}$ & $\begin{array}{l}0.33 * * \\
(0.02)\end{array}$ & $\begin{array}{l}0.20^{* *} \\
(0.02)\end{array}$ & $\begin{array}{l}0.13 * * \\
(0.02)\end{array}$ & $\begin{array}{l}0.27 * * \\
(0.02)\end{array}$ \\
\hline Mother & $\begin{array}{l}0.20^{*} \\
(0.04)\end{array}$ & $\begin{array}{l}0.40 * * \\
(0.04)\end{array}$ & $\begin{array}{l}0.42^{* * *} \\
(0.04)\end{array}$ & $\begin{array}{l}0.33 * * \\
(0.02)\end{array}$ & $\begin{array}{l}0.27 * * \\
(0.03)\end{array}$ & $\begin{array}{l}0.22 * * \\
(0.03)\end{array}$ & $\begin{array}{l}0.20 * * \\
(0.02)\end{array}$ & $\begin{array}{l}0.25 * * \\
(0.03)\end{array}$ & $\begin{array}{l}0.30 * * \\
(0.04)\end{array}$ \\
\hline DG & $\begin{array}{l}0.04 \\
(0.04)\end{array}$ & $\begin{array}{l}0.00 \\
(0.06)\end{array}$ & $\begin{array}{l}0.00 \\
(0.07)\end{array}$ & $\begin{array}{l}0.33 \\
(0.08)\end{array}$ & $\begin{array}{l}0.09 \\
(0.10)\end{array}$ & $\begin{array}{l}0.22^{*} \\
(0.10)\end{array}$ & $\begin{array}{l}0.00 \\
(0.09)\end{array}$ & $\begin{array}{l}0.00 \\
(0.07)\end{array}$ & $\begin{array}{l}0.00 \\
(0.06)\end{array}$ \\
\hline Obs & 4,097 & 4,097 & 4,097 & 4,097 & 4,097 & 4,097 & 4,097 & 4,097 & 4,097 \\
\hline
\end{tabular}

Std. errors are in parentheses. Sig. levels: $* * 1 \%, * 5 \%$.

The fact that $\beta_{F}$ and $\beta_{M}$ first increase and then decrease is consistent with the idea of a logistic relationship between $S_{F, i}$ and $S_{M, i}$. Therefore, to test and characterize the relationship between parental schooling and child's education, we use a semiparametric model in which $S_{F, i}$ and $S_{M, i}$ enter the nonparametric part.

Table 3 summarizes the semi-parametric analysis. The estimated degrees of freedom of the nonparametric parts (NP) show that nonlinearities are particularly strong for mother's education. One possible explanation could be the fact that time devoted by a father to children is less sensible to his educational attainment. (Note 6) Nonlinearities are even stronger when we use our alternative samples: NLSY and PSID.

Table 3. Semi-parametric regression

\begin{tabular}{llll}
\hline & WLS & NLSY & PSID \\
\hline Intercept & $14.46^{* *}$ & $14.44^{* *}$ & 13.91 \\
& $(0.04)$ & $(0.60)$ & $(0.15)$ \\
Father & NP** & NP** & NP** \\
& Edf $=3.67$ & Edf $=7.31$ & Edf $=4.16$ \\
Mother & NP** & NP** & NP** \\
& Edf $=5.87$ & Edf $=8.85$ & Edf $=4.08$ \\
DG & 0.09 & - & - \\
& $(0.06)$ & 2635 & 1936 \\
Obs & 4,097 & 0.21 & 0.27 \\
R-sq.(adj) & 0.23 & 3.61 & 2.61 \\
GCV-score & 4.11 & &
\end{tabular}

Std. errors are in parentheses. Sig. levels: ${ }^{* *} 1 \%, * 5 \%$.

Edf (Estimated Degrees of Freedom) 
Figure 2 reports the smooth components of Equation (3) for our main sample (WLS). Vertical axes are on the scale of the linear predictor.
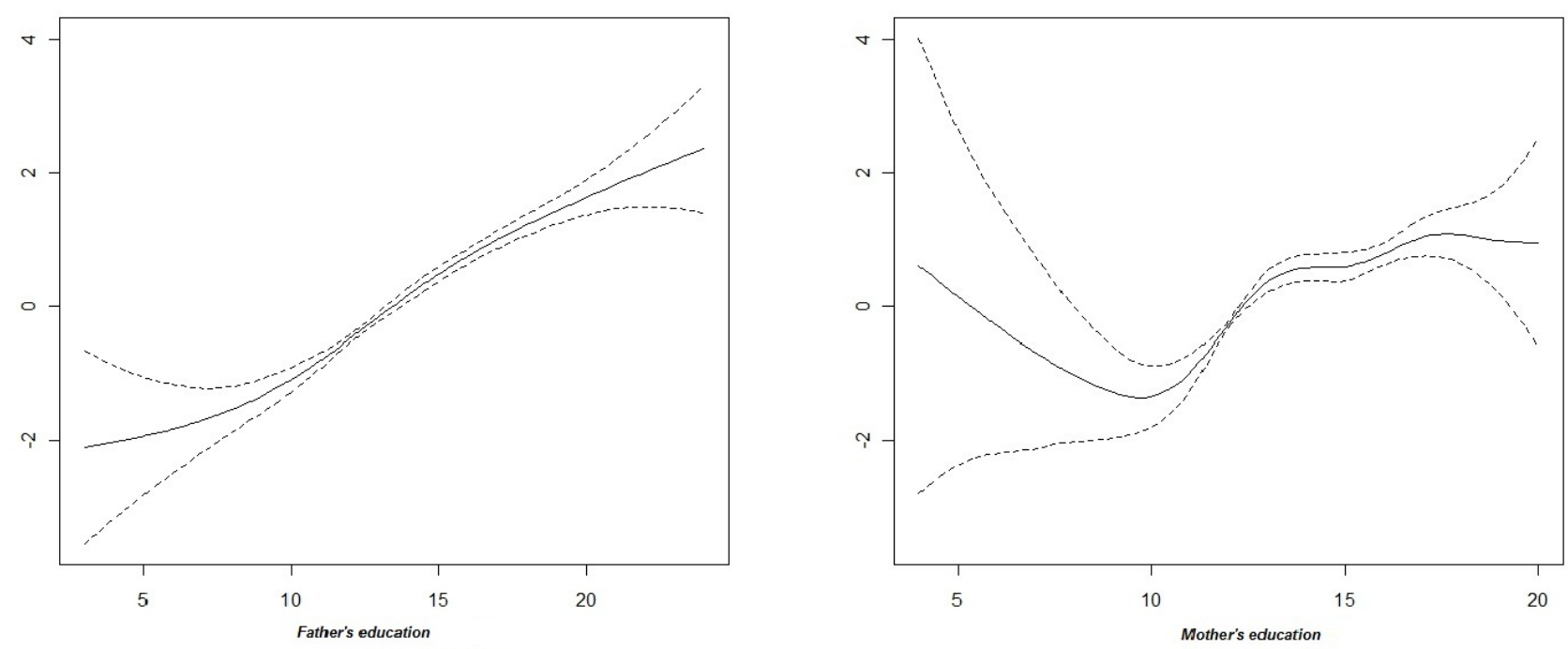

Figure 2. Nonparametric estimates (GAM)

As expected, Figure 2 shows that the relationship between parental education and child's education is nonlinear. These estimates are in line with the quantile regressions, confirming the robustness of our conclusions.

\section{Discussion}

This article was motivated by concerns that previous studies on intergenerational schooling mobility implicitly assumed that the relationship between parental education and child's education was linear. By estimating a quantile regression and a generalized additive model, we found that this relationship is nonlinear. This result does not change when we use different samples. As suggested by some overlapping generation models on poverty traps, this relationship is first convex and then concave. That is, returns to parental background are first increasing and then decreasing. In particular, the relationship between mother's education and children's education seems to be extremely nonlinear. Although the impact of mother's education on child's education is generally higher than father's one, the opposite holds when we consider median estimators. These results explain why the literature is not conclusive on this topic. That is, empirical findings depend on the composition of the sample.

Independently of causality issues, this article has important methodological implications for future studies. Indeed, researchers should take into account the existence of nonlinearities in the intergenerational transmission of education. That is, since linear models can lead to extremely biased estimates, they should use more flexible specifications.

\section{References}

Aiyar, S. (2003). The human capital constraint: of increasing returns, education choice and coordination failure. Topics in Macroeconomics, 3, 1071. http://dx.doi.org/10.2202/1534-5998.1071

Azariadis, C., \& Drazen, A. (1990). Threshold Externalities in Economic Development. The Quarterly Journal of Economics, 105, 501-526. http://dx.doi.org/10.2307/2937797

Barrodale, I., \& Roberts, F. D. K. (1974). Solution of an overdetermined system of equations in the 11 norm, Communications of the ACM, 17, 319-320.

Bassetti, T. (2012). Education as a social agreement. The Journal of Socio-Economics, 41(2012), 8-17. http://dx.doi.org/10.1016/j.socec.2011.10.005

Becker, G. S., \& Tomes, N. (1979). An Equilibrium Theory of the Distribution of Income and Intergenerational Mobility. Journal of Political Economy, 87(6), 1153-1189. http://dx.doi.org/10.1086/260831

Becker, G. S., \& Tomes, N. (1986). Human Capital and the Rise and Fall of Families. Journal of Labor Economics, 4(3), S1-S38. http://dx.doi.org/10.1086/298118 
Behrman, J. R., \& Taubman, P. (1989). Is Schooling 'Mostly in the Genes'? Nature-Nurture Decomposition with Data on Relatives. Journal of Political Economy, 97, 1425-1446. http://dx.doi.org/10.1086/261661

Behrman, J. R., \& Rosenzweig, M. R. (2002). Does Increasing Women's Schooling Raise the Schooling of the Next Generation?. The American Economic Review, 92, 323-334. http://dx.doi.org/10.1257/000282802760015757.

Betts, J. R., \& Grogger, J. (2003). The impact of grading standards on student achievement, educational attainment, and entry-level earnings. Economics of Education Review, 22, 343-352. http://dx.doi.org/10.1016/S0272-7757(02)00059-6

Björklund, A., Lindahl, M., \& Plug, E. (2006). The Origins of Intergenerational Associations: Lessons from Swedish Adoption Data. The Quarterly Journal of Economics, 121(3), 999-1028. http://dx.doi.org/10.1162/qjec.121.3.999.

Carneiro, P., Crawford, C., \& Goodman, A. (2007). The impact of early cognitive and non-cognitive skills on later outcomes. London: Centre for the Economics of Education, LSE.

Conger, R.D., Ebert-Wallace, L., Sun, Y., Simons, R. L., McLoyd, V. C., \& Brody, G. H. (2002). Economic pressure in African American families: A replication and extension of the family stress model. Developmental Psychology, 38, 179-193. http://dx.doi.org/10.1037//0012-1649.38.2.179

De Haan, M., \& Plug, E. (2011). Estimating intergenerational schooling mobility on censored samples: consequences and remedies. Journal of Applied Econometrics, 26, 151-166. http://dx.doi.org/10.1002/jae.1123

Davis-Kean, P. E. (2005). The Influence of Parent Education and Family Income on Child Achievement: The Indirect Role of Parental Expectations and the Home Environment. Journal of Family Psychology, 19(2), 294-304. http://dx.doi.org/10.1037/0893-3200.19.2.294

Galor, O., \& Zeira, J. (1993). Income Distribution and Macroeconomics. Review of Economic Studies, 60, 35-52. http://dx.doi.org/10.2307/2297811

Halle, T., Kurtz-Costes, B., \& Mahoney, J. (1997). Family influences on school achievement in low-income, African American children. Journal of Educational Psychology, 89, 527-537. http://dx.doi.org/10.1037/0022-0663.89.3.527

Hastie, T., \& Tibshirani, R. (1986). Generalized additive models (with discussion). Statistical Science, 1, 297-318. http://dx.doi.org/10.1214/ss/1177013604

Hastie, T., \& Tibshirani, R. (1990). Generalized Additive Models. Chapman \& Hall, London.

Haveman, R., \& Wolfe, B. (1995). The Determinants of Children Attainments: A Review of Methods and Findings. Journal of Economic Literature, 33(4), 1829-1878.

Koenker, R. W., \& d'Orey, V. (1987). Computing regression quantiles. Applied Statistics, 36, 383-393. http://dx.doi.org/10.2307/2347802

Linver, M. R., Brooks-Gunn, J., \& Kohen, D. E. (2002). Family processes as pathways from income to young $\begin{array}{lllll}\text { children's development. Developmental } & \text { Psychology, } & 38, & \text { 719-734. }\end{array}$ http://dx.doi.org/10.1037//0012-1649.38.5.719

Mistry, R. S., Vandewater, E. A., Houston, A. C., \& McLoyd, V. C. (2002). Economic well-being and children's social adjustment: The role of family process in an ethnically diverse low income sample. Child Development, 73, 935-951. http://dx.doi.org/10.1111/1467-8624.00448

Murphy, K., Shleifer, A., \& Vishny, R. (1989). Industrialization and the Big Push. Journal of Political Economy, 97, 1003-1026. http://dx.doi.org/10.1086/261641

Newey, W. K., \& Powell, J. L. (1990). Efficient estimation of linear and type I censored regression models under

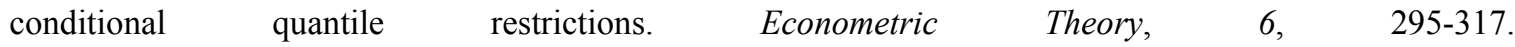
http://dx.doi.org/10.1017/S0266466600005284

Plug, E., \& Vijverberg, W. (2003). Schooling, Family Background, and Adoption: Is It Nature or Is It Nurture? Journal of Political Economy, CXI, 611-641. http://dx.doi.org/10.1086/374185

Redding, S. (1996). The low-skill, low-quality trap: strategic complementarities between human capital and R\&D. The Economic Journal, 106, 458-470. http://dx.doi.org/10.2307/2235260 
Sacerdote, B. (2002). The Nature and Nurture of Economic Outcomes. American Economic Review Papers and Proceedings, 92, 344-348. http://dx.doi.org/10.1257/000282802320191589

Solon, G. (1999). Intergenerational Mobility in the Labor Market. In O. Ashenfelter, \& D. Card (eds.), Handbook of Labor Economics (Vol. III). Amsterdam: North-Holland. http://dx.doi.org/10.1016/S1573-4463(99)03010-2

Wood, S. N. (2006). Generalized Additive Models: An Introduction with R. Chapman \& Hall, London.

Yeung, W. J., Linver, M. R., \& Brooks-Gunn, J. (2002). How money matters for young children's development: Parental investment and family processes. Child Development, 73, 1861-1879. http://dx.doi.org/10.1111/1467-8624.t01-1-00511

\section{Notes}

Note 1. Other models with equilibrium multiplicity in the accumulation of human capital are Murphy et al. (1989), Redding (1996), Aiyar (2003) and Bassetti (2012). These models attribute the existence of nonlinearities to the lack of coordination among economic agents.

Note 2. This technique was first proposed by Hastie and Tibshiran $(1986,1990)$, along with estimation methods and inference.

Note 3. See Koenker and d'Orey (1987) for a detailed description of this algorithm.

Note 4. The number of non-positive values was 50 out of 4,097 .

Note 5 . Also a bootstrap method based on 200 replications confirms the validity of our results.

Note 6. There are no relevant interaction effects between mother and father's education. 